W. John Judd ${ }^{\mathrm{a}}$

E. Ann Steiner ${ }^{\text {a }}$

Clark E. Nugent ${ }^{\text {b }}$

a Departments of Pathology and

${ }^{b}$ Obstetrics and Gynecology,

University of Michigan, Ann Arbor, Mich., USA

We read with interest the recent report by Garner et al. [1], in which anti-E was detected early in pregnancy solely through the use of enzymetreated red blood cells (RBC). The serological reactivity of this anti-E changed dramatically during pregnancy; the antibody became detectable by the indirect antiglobulin test, and at 37 weeks' gestation had a titer of 512. Delivery at 40 weeks' gestation yielded an infant affected with hemolytic disease of the newborn (HDN) requiring exchange transfusion and 4 days of phototherapy. This case was further complicated by anti$\mathrm{K} 1$, stimulated by prior transfusions, that was present throughout the pregnancy but did not contribute to the HDN, and an anti-c that was detected solely in tests with enzyme-treated RBCs at 35 weeks' gestation, but was not demonstrable in the infant at delivery.

While we concur with the authors that there is a need to screen both $\mathrm{Rh}$ $\mathrm{D}$-positive and Rh D-negative women for RBC alloantibodies early in pregnancy, and while we agree that once an antibody has been detected it should be identified and evaluated for its potential to cause HDN, we

\title{
Appropriate Serological Testing in Pregnancy
}

cannot condone the routine use of enzyme-treated RBCs when screening for unexpected antibodies for the following reasons. First, we are unaware of documented cases in which an anti-D was detected for the first time at 28 weeks' gestation solely by tests with enzyme-treated RBC, yet there was severe HDN that warranted medical intervention (e.g. intrauterine transfusion, induction) before full-term delivery. Second, we are unaware of documented cases in which an antibody other than anti-D was detected solely by tests with enzymetreated RBC during the first trimester, yet there was severe HDN that warranted medical intervention before full-term delivery. Since medical intervention was not reported to have taken place in the case described by Garner et al. [1], we remain so unaware. Third, Issitt [2] recently confirmed what most USA investigators have long claimed: the incidence of unwanted positive tests is such that use of enzyme-treated RBC for antibody detection is not warranted in an era of limited resources. Moreover, further support for our position is to be found in the 1990 guidelines promulgated by a committee of the Scien- tific Section of the American Association of Blood Banks [3].

These guidelines recommend testing prenatal patients for unexpected antibodies during the first trimester by methods that detect antibodies known to cause HDN. Routine testing for unexpected antibodies later in pregnancy is recommended for $\mathrm{Rh} \mathrm{D}$ negative women, at 28-30 weeks' gestation, to document the absence of alloimmunization to $D$ and verify the need for prophylactic $\mathrm{Rh}$ immune globulin therapy. Because of the paucity of alloantibodies other than $D$ that necessitate medical intervention before full-term delivery [4], the cost-effectiveness of routinely testing $\mathrm{Rh} \mathrm{D}$-positive prenatal patients again for unexpected alloantibodies during the third trimester must be questioned. However, such testing is recommended for all pregnant women, regardless of Rh type, when there is a history of previous transfusions or traumatic deliveries. Also, periodic testing for additional antibodies during the third trimester is recommended for women with preexisting alloantibodies or a history thereof $[2,5]$.

Under these latter protocols, the patient described by Garner et al. [1] 
would have been retested during the third trimester, since there was both a history of transfusion and a preexisting anti-K1. One can assume that the anti-E would have been detected by indirect antiglobulin test with untreated RBCs, but even if these follow-up studies were not performed or were nonreactive, the outcome and clinical management of the pregnancy would have been no different than that reported. In spite of the high anti-E titers and antibody-dependent cell cytotoxicity (ADCC) assay values, there was no reported medical intervention during the latter stages of the pregnancy, nor did the authors report that they monitored for HDN by nonserological means, such as amniotic fluid analysis, ultrasonography or percutaneous umbilical blood sampling.

Thus, we must also question the value of performing titration studies after the antibody titer exceeds the critical value of 16. For Rh antibodies, this is the level above which, in the USA, fetal monitoring by nonserological means is considered indicated $[2,5,6]$. Rather than performing time-consuming and unnecessary titration studies, it would seem more appropriate to manage cases similar to the one under discussion by mon- itoring the anti-E until it exceeds the critical titer, after which no further titrations are performed. Instead, subsequent assessment for the potential for HDN should include amniotic fluid analysis, ultrasonography or percutaneous umbilical blood sampling, as indicated. Under such a regimen, the need for fetal transfusions or early delivery can be addressed in order to minimize the potential physiological, hematological and neurological adverse effects associated with untreated HDN.

Clearly there are fundamental differences between the UK and USA health-care delivery systems. What is deemed appropriate in one setting may be impractical in another. However, efforts to curtail escalating costs are of paramount concern to healthcare workers in both countries. On this side of the Atlantic, we would question not only the recommended tests with enzyme-treated RBC and the needless anti-E titrations, but also the titration of anti-K1 when the father is $K:-1$, the value of the ADCC assay when alleged significant data do not prompt medical intervention of pregnancy, and the performance of cord blood elution studies when maternal alloantibodies are clearly identified.
It could be argued that the anti-K1 might contribute to HDN if the husband was not the father, but if paternity is in question there seems little value in phenotyping the husband's RBC to begin with! Doubtless the $\mathrm{ADCC}$ data are interesting and informative, but what is their utility? Similarly, the elution data are of interest, and document the noninvolvement of anti-K1 in contributing to the hemolytic disease; however, regardless of the specificity of antibodies recovered by elution, appropriate transfusion management of the infant necessitates the selection of E- and K:-1 blood.

In the current economic environment it is prudent, if not essential, to eliminate tests unless the data obtained will aid in diagnosis or be used to modify patient care [7]. In the case under review [3], many of the data generated fail to satisfy either criteria.

Prof. W. John Judd Department of Pathology, UH-2G332 University Hospitals 1500 East Medical Center Drive Ann Arbor, MI 48109-0054 (USA)

\section{References}

1 Garner SF, Devenish A, Barber H, Contreras M: The importance of monitoring 'enzymeonly' red cell antibodies during pregnancy. Vox Sang 1991:61:219-220.

2 Judd WJ, Luban NLC, Ness PM, Silberstein LE, Stroup M, Widmann FK: Prenatal and perinatal immunohematology: Recommendations for serologic management of the fetus, newborn infant, and obstetric patient. Transfusion 1990;30:175-183.
3 Issit PD; Lack of clinical significance of 'enzyme-only' red cell antibodies. Transfusion 1991;31(S):39.

4 Walker RH: Relevancy in the selection of serologic tests for the obstetric patient; in Garratty $G$ (ed): Hemolytic Disease of the Newborn. Arlington, American Association of Blood Banks, 1984, pp 173-203.

5 Management of isoimmunization in pregnancy. Tech Bull No 148. Washington, American College of Obstetricians and Gynecologists, 1990.
6 Freda VJ: The antepartum management of hemolytic disease; in Garratty $G$ (ed): Hemolytic Disease of the Newborn. Arlington, American Association of Blood Banks, 1984, pp 33-51.

7 Oberman HA, Judd WJ: Cost-containment in transfusion practice: A view from the United States; in Cash JD (ed): Progress in Transfusion Medicine. Edinburgh, Churchill-Livingstone, 1988; vol 3, pp 145-174. 